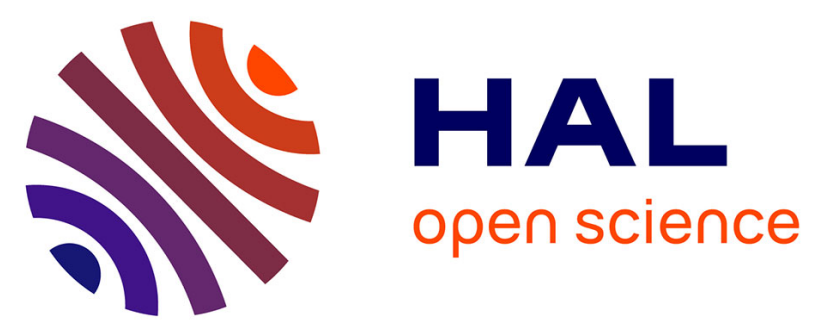

\title{
Atypical Properties of FIB-Patterned RuOx Nanosupercapacitors
}

Anaïs Ferris, Benjamin Reig, Asma Eddarir, Jean-François Pierson, Sébastien Garbarino, Daniel Guay, David Pech

\section{- To cite this version:}

Anaïs Ferris, Benjamin Reig, Asma Eddarir, Jean-François Pierson, Sébastien Garbarino, et al.. Atypical Properties of FIB-Patterned RuOx Nanosupercapacitors. ACS Energy Letters, 2017, 2 (8), pp.1734-1739. 10.1021/acsenergylett.7b00435 . hal-01872884

\section{HAL Id: hal-01872884 \\ https://hal.laas.fr/hal-01872884}

Submitted on 12 Sep 2018

HAL is a multi-disciplinary open access archive for the deposit and dissemination of scientific research documents, whether they are published or not. The documents may come from teaching and research institutions in France or abroad, or from public or private research centers.
L'archive ouverte pluridisciplinaire HAL, est destinée au dépôt et à la diffusion de documents scientifiques de niveau recherche, publiés ou non, émanant des établissements d'enseignement et de recherche français ou étrangers, des laboratoires publics ou privés. 


\section{Atypical Properties of FIB-Patterned $\mathrm{RuO}_{\mathrm{x}}$ Nanosupercapacitors}

Anaïs Ferris, ${ }^{\dagger+}$ Benjamin Reig, ${ }^{\dagger}$ Asma Eddarir,${ }^{\dagger}$ Jean-François Pierson, ${ }^{\S}$ Sébastien Garbarino,,+ Daniel Guay, ${ }^{*}$ and David Pech ${ }^{*}+$

'LAAS-CNRS, Université de Toulouse, CNRS, Toulouse, France

INRS-énergie, Matériaux, Télécommunications, 1650 Boulevard Lionel Boulet, Varennes, QC J3X 1S2, Canada

${ }^{\S}$ Institut Jean Lamour (UMR CNRS 7198), Université de Lorraine, Parc de Saurupt, 54011

Nancy cedex, France 
ABSTRACT: Small-scale electrochemical capacitors, also called microsupercapacitors, have been the subject of intense research in the last few years as miniaturized energy storage components for modern electronics. Although numerous microfabrication processes have been successfully assessed to achieve low-profile supercapacitors with sub-millimeter scale features, several advances still need to be made in their performance characteristics to become industrially viable components. Here we report the occurrence of unexpected properties of on-chip supercapacitors when reducing inter-electrode spacing down to the nanometer-scale. An ultrahigh power concomitant with a high capacitance and energy density, an unforeseeable extended cell voltage and an impressive lifetime were obtained at such small dimensions with a FIBpatterned nanosupercapacitor based on $\mathrm{RuO}_{x}$ pseudocapacitive material. The scaling relationship between miniaturized supercapacitors and electrochemical responses leads to valuable understanding of electrode reactions and rate-limiting steps. This finding offers new opportunities in the design of integrated energy storage devices with improved properties. 
While the demand for ever-smaller electronic devices has pushed to the miniaturization of a variety of technologies, energy-storage units have lagged behind in this downsizing tendency. ${ }^{1}$ Developing energy-storage elements for self-powered nanosystems, such as nanoelectromechanical systems $(\mathrm{NEMS})^{2}$ or wireless nanosensor networks, ${ }^{3}$ is of critical importance in many areas of applications, ranging from home automation and industrial tracking to healthcare and environmental monitoring. As the size of power source should be commensurate with the device it powers, great efforts have been recently devoted to integrating energy harvesting ${ }^{4}$ and storage ${ }^{5}$ nanodevices with the objective to build densely integrated electronic systems having total energy autonomy.

Electrochemical capacitors, also called supercapacitors, are reversible energy-storage devices with a high power density, fast charge and discharge rates, and long service life compared to batteries. ${ }^{6-8}$ Nanoscale supercapacitors are consequently of great interest in the development of nanoscale sensor systems requiring the delivery of peak power and long operating lifetime. For nanoscale supercapacitors, it is imperative to consider all reported properties (capacitance, energy, power...) normalized to the footprint area on the chip. However, fabrication of miniaturized planar electrodes at very small scale is a challenge on its own. Optical lithographic efforts have led to the development of microscopic thin-film supercapacitors, ${ }^{9,10}$ however the resolution of conventional photolithography techniques is limited by the diffraction of light, which makes it difficult for them to meet the demand of fabricating ultra-high density integrated devices. Actually, most of the "microsupercapacitors" reported in the literature have photolithographic feature size well above $10 \mu \mathrm{m}$ and typical footprint occupancy of $c a .1 \mathrm{~cm}^{2} .{ }^{11}$ To overcome size limitation, an interesting approach is to combine optical lithography with the 
use of focused ion beam (FIB) technology to directly scribe a high-resolution pattern onto a deposited thin film electrode. ${ }^{12}$

Several carbonaceous ${ }^{13-16}$ and pseudocapacitive materials ${ }^{17,18}$ have been evaluated for miniaturized supercapacitors, considering the choice of materials is one of the factors that ensure high performance. Among them, ruthenium oxide, $\mathrm{RuO}_{\mathrm{x}}$, appears to be the most promising material owing to its high specific capacitance, highly reversible redox reactions and long cycling life. Even if its high cost has limited its development for large-size supercapacitors, the use of this material becomes relevant for miniaturized supercapacitors where only tiny amount of active material is required.

Here we describe the FIB-fabrication of a nanosupercapacitor based on ruthenium oxide that exhibits singular properties. The manufacturing approach allows the diminution of the cell dimension by six orders of magnitude (from square centimeters to few tens of square micrometers) and the reduction of the inter-electrode spacing by two orders of magnitude (from tens of micrometers to hundreds of nanometers). We show that this scaling down reduces the ohmic losses and improves the energy storage efficiency of the electrochemical devices. We also focus on the anomalous extension of cell voltage observed at very high charge/discharge rate.

A Cr/Pt (40/200 nm) thin film was deposited by evaporation on an oxidized silicon substrate $\mathrm{Si} / \mathrm{SiO}_{2}(500 \mathrm{~nm})$, followed by the deposition of a $100 \mathrm{~nm}$-thick metallic $\mathrm{Ru}$ by magnetron sputtering under a total pressure of $1 \mathrm{~Pa}$ without additional heating. ${ }^{19}$ The electrical resistivity of Ru was measured to be $c a .40 \mu \Omega . c m$. Using a suitable lithographic process and an optimized ion beam (Supporting Figure S1 and S2), a narrow gap of $50 \mathrm{~nm}$ was created by FIB sputter etching in the thin film of $\mathrm{Pt} / \mathrm{Ru}$ material with a well-defined pattern, as illustrated in Figure 1 . The $\mathrm{Ru}$ was then electrochemically oxidized into hydrous ruthenium oxide $\mathrm{RuO}_{\mathrm{x}}$ (Supporting Figure S3) 
before being heat-treated at $150^{\circ} \mathrm{C}$ for $1 \mathrm{~h}$. A protective insulating SU-8 masking layer was subsequently deposited to define an electrochemically active surface exposed to the electrolyte, delimiting a final device area of $25 \mu \mathrm{m}^{2}$ (i.e. potentially enabling 4 million units per $\mathrm{cm}^{2}$ ).

Figure 2a shows the Nyquist plot of the FIB nanosupercapacitor, with an exceptionally low equivalent series resistance (ESR, Figure 2a inset) of $821 \Omega . \mu \mathrm{m}^{2}\left(\right.$ i.e. $\left.8.2 \mu \Omega . \mathrm{cm}^{2}\right)$ and a perfect vertical increase of the impedance in the low-frequency region. The corresponding specific power density is $304 \mu \mathrm{W} / \mu \mathrm{m}^{2}$ (i.e. $30.4 \mathrm{~kW} / \mathrm{cm}^{2}$ ) for a cell voltage of $1 \mathrm{~V}$, which is the highest value ever reported for miniaturized on-chip supercapacitors and more than four orders of magnitude higher than state-of-the-art microsupercapacitors. ${ }^{11,20-23}$ This prodigious power ability of nanosupercapacitors is explained by the ultra-small physical separation isolating the positive and the negative electrode, which leads to a dramatic reduction of the cell constant and the ESR, as demonstrated in our previous works. ${ }^{24}$ However, ultra-high power values should always be treated with caution. There is a trade-off between power and capacitance, and the ultimate performance improvement is to increase the areal power density without sacrificing the areal energy of the device. ${ }^{9}$ In the low frequency region, an increase of the imaginary portion of the impedance is observed with a slope close to $90^{\circ}$, as it is expected for capacitive behavior with no leakage current. At such high impedance, the contribution of the dielectric capacitance of the underlying $\mathrm{SiO}_{2}$ layer, $C_{d}$, cannot be neglected. The measured capacitance, $C$, is therefore the sum of two capacitances in parallel, the dielectric capacitance and the pseudocapacitance of the nanosupercapacitor, $C_{s c}$, so that $C=C_{d}+C_{s c}$. Taking into account $C_{d}$, the cell capacitance deduced from the impedance spectrum at $100 \mathrm{mHz}$ is $180 \mathrm{pF} / \mu \mathrm{m}^{2}$ (i.e. $18 \mathrm{mF} / \mathrm{cm}^{2}$ ), which is an excellent value compared to those reported for thin-film microsupercapacitors. ${ }^{9,25}$ The high specific power of the nanosupercapacitor is thus concomitant with a high specific capacitance 
with a very low time constant $\tau=E S R . C$ of $148 \mathrm{~ns}$. The aptitude to combine high areal energy and high areal power density is also illustrated by the ability of the nanosupercapacitor to maintain a capacitive behavior at both low (Figure $2 b$ ) and ultra-high scan rates (Figure 2c). At low scan rates, the cyclic voltammograms (CVs) display the quasi-perfect rectangular shape of an ideal capacitor with no ESR. The cell capacitance, estimated from the CV, achieves a reproducible value of $40 \mathrm{pF} / \mu \mathrm{m}^{2}$ (i.e. $4 \mathrm{mF} / \mathrm{cm}^{2}$ ) when cycled at $5 \mathrm{mV} / \mathrm{s}$, and an excellent areal energy density of $20 \mathrm{pJ} / \mu \mathrm{m}^{2}$ (i.e. $2 \mathrm{~mJ} / \mathrm{cm}^{2}$ ) for a $1 \mathrm{~V}$ cell voltage. The volumetric capacitance is estimated to be around $222 \mathrm{pF} / \mu \mathrm{m}^{3}$ (i.e. $222 \mathrm{~F} / \mathrm{cm}^{3}$ ) which is slightly lower to the theoretic value of hydrated ruthenium oxide. ${ }^{26}$ The capacitive behavior was also maintained at ultra-high voltage scan rates exceeding $20 \mathrm{~V} / \mathrm{s}$ with good reversibility, as reported for high-power microsupercapacitors designed to meet the specifications of ac line-filtering applications. ${ }^{27-30}$

Another unexpected consequence of using nanopatterned supercapacitor is the extent of the cell voltage. We evaluated the electrochemical behavior of the $\mathrm{RuO}_{\mathrm{x}}$ based nanosupercapacitor at $10 \mathrm{~V} / \mathrm{s}$ with increasing voltage window (Figure 3a). Surprisingly, the nanodevice was able to cycle up to $1.7 \mathrm{~V}$ in aqueous sulfuric acid electrolyte with no visible sign of degradation due to water electrolysis. This result challenges the long-held axiom that supercapacitors based on aqueous electrolyte have a restricted operating voltage range of $c a .1 \mathrm{~V}$ because of the electrochemical decomposition of water at higher potentials. ${ }^{31,32}$ Moreover, an intriguing phenomenon is that the abrupt current increase related to water splitting appears to move towards higher voltage values with increasing scan rates, from $c a .1 \mathrm{~V}$ at $100 \mathrm{mV} / \mathrm{s}$ up to $c a .1 .9 \mathrm{~V}$ at $50 \mathrm{~V} / \mathrm{s}$ (Figure 3b). Since the stored energy $E$ increases with the square of the voltage $\left(E=1 / 2 C \cdot V_{0}^{2}\right)$, this extension of the nanosupercapacitor voltage leads to a $261 \%$ increase in energy. As a result, the nanosupercapacitor has far more energy when high power delivery is 
required in very short times. This behavior is in total disagreement with conventional supercapacitors and microsupercapacitors where the specific energy decreases with increase in specific power because of kinetic and resistance issues. ${ }^{33}$

To understand and analyze this unusual behavior, we have considered the sweep rate dependence of the recorded current at different cell voltages (from 1 to $1.9 \mathrm{~V}$ ) as shown in Figure 4. A linear dependency between $\log ($ current $i)$ and $\log (\operatorname{scan}$ rate $v)$ is observed for a cell voltage of $1 \mathrm{~V}$ in aqueous sulfuric acid electrolyte. The slope of the $\log (i) v s . \log (v)$ plot is 0.96 on the whole sweep-rate range (from $50 \mathrm{mV} / \mathrm{s}$ to $20 \mathrm{~V} / \mathrm{s}$ ), indicating that the overall response tends to be capacitive as expected for a pseudocapacitive material tested within the domain of thermodynamic stability of water. When the nanosupercapacitor is tested at much higher voltages, i.e. well above the upper limit for water decomposition $\left(\mathrm{H}_{2} \mathrm{O}\right)$ into oxygen $\left(\mathrm{O}_{2}\right)$ and hydrogen $\left(\mathrm{H}_{2}\right)$ gas, an additional faradaic current contribution appears. In Figure 4 , this is evidenced by a region at low scan rates where $\log (i)$ is independent of scan rate. The faradaic current if increases steadily with the cell voltage (from 1.5 to $1.9 \mathrm{~V}$ ), suggesting the reaction is under kinetic control. ${ }^{34}$ Accordingly, for a fixed cell voltage $V_{0} \geq 1.5 \mathrm{~V}$, the current response is the sum of two contributions, a pseudocapacitive current $\left(i_{c}\right)$ originating from ruthenium oxide and a faradaic current $\left(i_{f}\right)$ resulting from water electrolysis. For $V_{0} \geq 1.5 \mathrm{~V}$, we can therefore observe two distinct behaviors according to the sweep-rate: at low and medium scan rates, the faradaic current of water electrolysis prevails on the capacitive current. However, the capacitive current $i_{c}=f(v)$ gets more and more important with increasing scan rates $v$ and becomes larger than the faradaic contribution at high scan rates (i.e. when $v>i_{f} / C$ ). Having a sub microsecond time constant $\tau$ of $148 \mathrm{~ns}$, the nanosupercapacitors are moreover able to maintain capacitive 
behaviors at ultra-high voltage scan rates $v \cdot{ }^{9}$ This phenomenon explains the atypical extension of the nanosupercapacitor voltage above $1.5 \mathrm{~V}$.

Furthermore, the ability to operate at such high voltage is illustrated by the remarkable lifetime of the device in harsh conditions - using galvanostatic charge/discharge cycles at $8 \mathrm{nA} / \mu \mathrm{m}^{2}$ (i.e. $0.8 \mathrm{~A} / \mathrm{cm}^{2}$ ) up to $1.5 \mathrm{~V}$. Figure 5 reveals the incredible stability of the device, with no capacitance loss even after ten thousands cycles of charge/discharge. Regarding the galvanostatic cycles, they all exhibit a symmetrical triangular curve with a nearly linear variation of voltage as a function of time at very high current densities, from 2 to $64 \mathrm{nA} / \mu \mathrm{m}^{2}$ (i.e. 0.2 to $6.4 \mathrm{~A} / \mathrm{cm}^{2}$ ) with a high specific energy reaching $130 \mathrm{pJ} / \mu \mathrm{m}^{2}$ (i.e. $13 \mathrm{~mJ} / \mathrm{cm}^{2}$ ) for the cell. The potential IR-drop at the current switching point is also negligible, confirming the extremely small ESR of the cell, as aforementioned.

In summary, we have demonstrated that supercapacitors undergo remarkable enhancement in their electrochemical performances when passing from micro to nanodimensions, with unusual and unique properties in terms of specific energy, power, lifetime and cell voltage. Our FIBpatterned nanosupercapacitor displays a cell capacitance of $180 \mathrm{pF} / \mu \mathrm{m}^{2}\left(\right.$ i.e. $\left.18 \mathrm{mF} / \mathrm{cm}^{2}\right)$ and can deliver an outstanding specific energy per surface area of $325 \mathrm{pJ} / \mu \mathrm{m}^{2}\left(32.5 \mathrm{~mJ} / \mathrm{cm}^{2}\right)$ thanks to a full utilization of the active material involved in the charge storage. The nanosupercapacitor exhibits also an ultralow ESR leading to a maximum power density of $304 \mu \mathrm{W} / \mu \mathrm{m}^{2}$ (i.e. $30.4 \mathrm{~kW} / \mathrm{cm}^{2}$ ), which is orders of magnitude higher than any result reported with alternative devices. Electrochemical investigations carried out in $0.5 \mathrm{M} \mathrm{H}_{2} \mathrm{SO}_{4}$ solution also confirmed the possibility to extend, under certain conditions, the operating voltage of up to $1.9 \mathrm{~V}$ in aqueous solution without any capacitance fade. Although these phenomena arising from nanoengineered supercapacitors have been validated with a $\mathrm{RuO}_{\mathrm{x}}$ pseudocapacitive material in aqueous sulfuric 
acid, the extension of the upper voltage limit could also be obtained with carbonaceous electrode materials and organic electrolytes working well above $2.3 \mathrm{~V}$. Consequently, these nanosupercapacitors open up new horizons in the expanding field of integrated nanoelectronics and nanosystems, such as nomad electronics, autonomous wireless sensor networks, biomedical implants, nanorobotics, NEMS, active radiofrequency identification (RF-ID) tags and embedded nanosensors. Moreover, the outstanding peculiarities obtained at very low dimensions can be exploited to design larger energy storage devices with probable improved properties by assembling arrayed nanosupercapacitors on large surfaces. Further improvements in the nanofabrication process with devices patterned in interdigitated configuration should also easily results in nano and microsupercapacitors with even higher areal energy and power. 


\section{FIGURES}

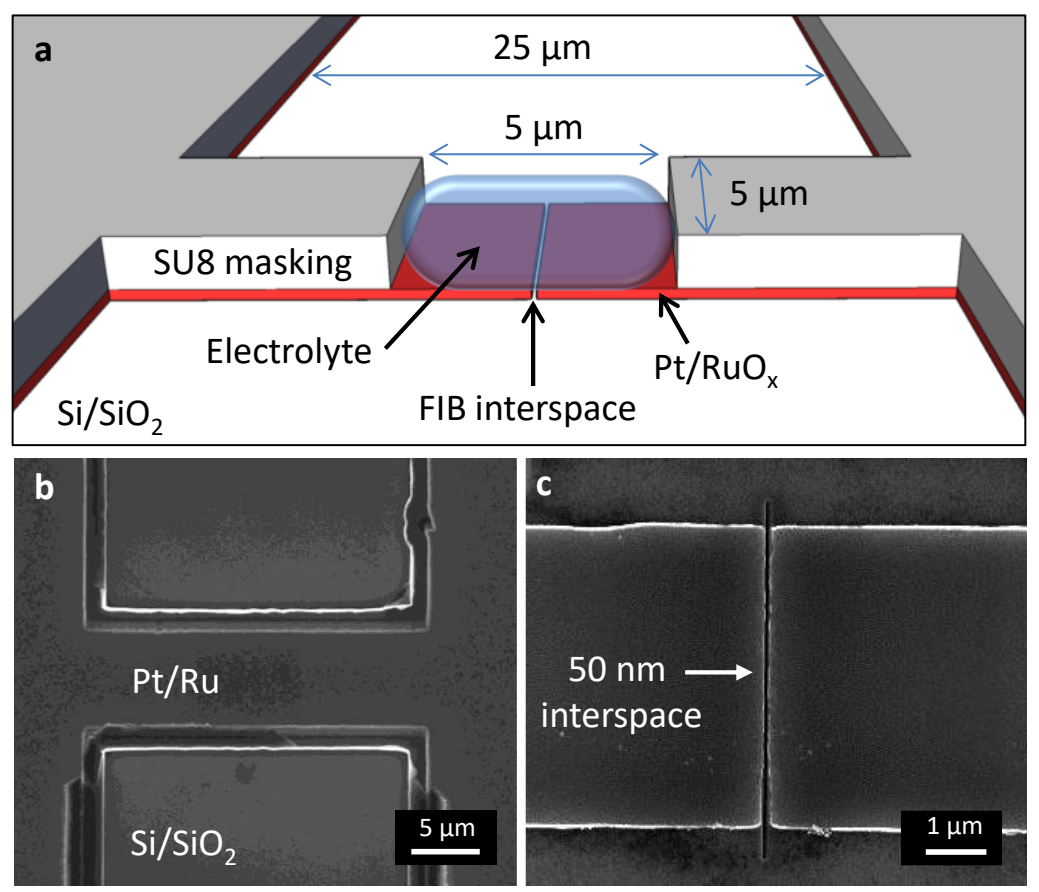

Figure 1. Design of planar nanosupercapacitors with $\mathrm{Pt} / \mathrm{RuO}_{\mathrm{x}}$ electrodes. (a) Schematic representation of the final nanodevice. (b, c) Scanning electron microscope image at different magnifications before the oxidation of Ru and the deposition of the SU-8 photoresist. 

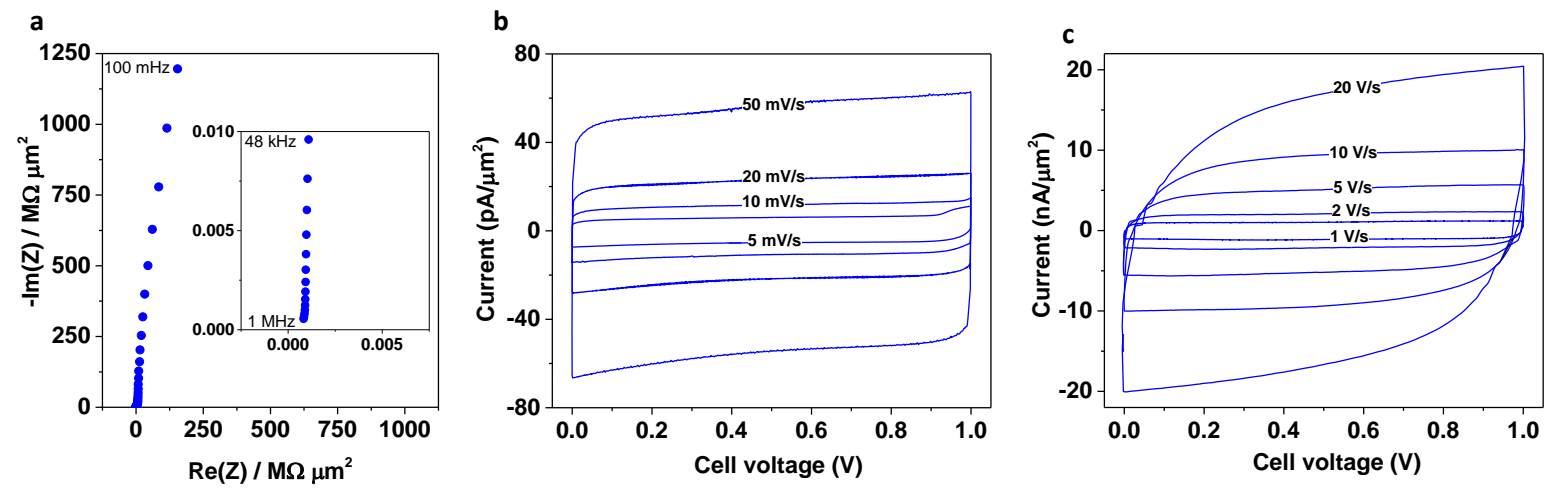

Figure 2. Electrochemical characterization of the nanosupercapacitor soaked in one drop of de-aerated $\mathrm{H}_{2} \mathrm{SO}_{4}$. (a) The Nyquist plot (inset: high frequency region) displays an exceptionally low ESR of $821 \Omega . \mu \mathrm{m}^{2}\left(8.2 \mu \Omega . \mathrm{cm}^{2}\right)$ with a vertical increase of the impedance. (b, c) Both CVs obtained at low (b) and ultra-high (c) scan rates exhibit a pronounced capacitive behavior, with a cell capacitance value of $40 \mathrm{pF} / \mu \mathrm{m}^{2}\left(4 \mathrm{mF} / \mathrm{cm}^{2}\right)$. 
a

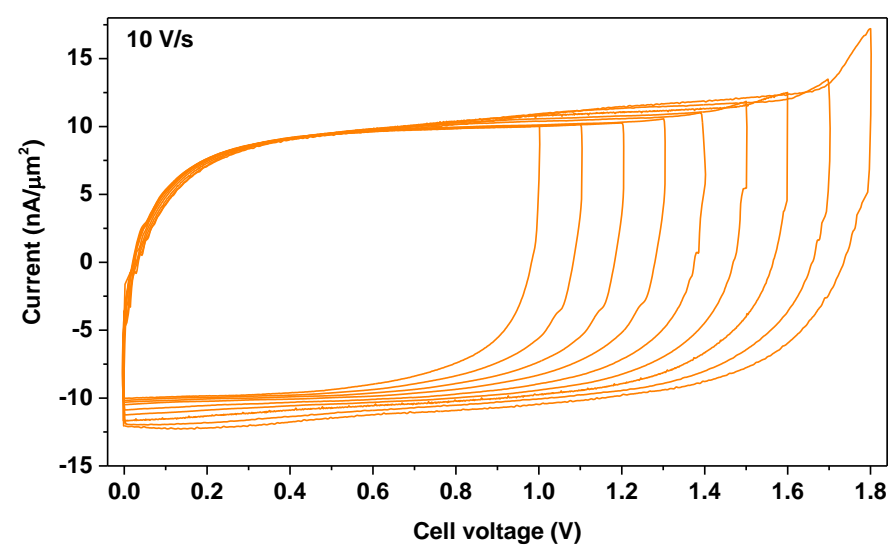

b

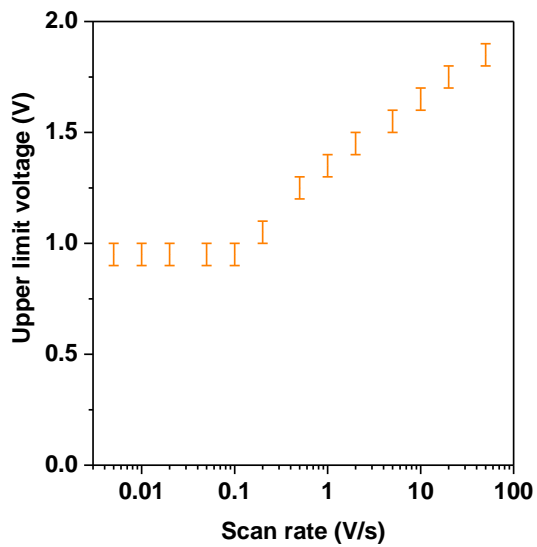

Figure 3. Anomalous extension of the nanosupercapacitor voltage in aqueous $\mathrm{H}_{2} \mathrm{SO}_{4}$ electrolyte.

(a) $\mathrm{CVs}$ obtained at $10 \mathrm{~V} / \mathrm{s}$ in $0.5 \mathrm{M} \mathrm{H}_{2} \mathrm{SO}_{4}$. The nanodevice is able to cycle up to $1.7 \mathrm{~V}$ with no oxidation/reduction peaks related to water electrolysis. (b) Evolution of the upper limit voltage vs. scan rate. The potential threshold moves toward higher values with increasing scan rates. 


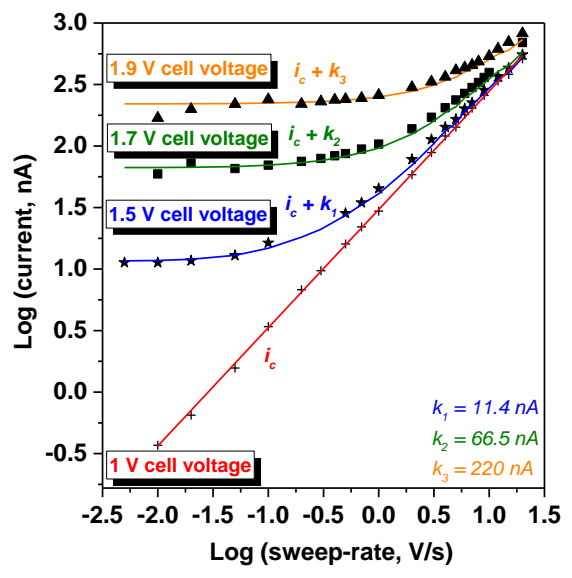

Figure 4. Sweep-rate dependence of the current of the nanosupercapacitor in de-aerated $0.5 \mathrm{M}$ $\mathrm{H}_{2} \mathrm{SO}_{4}$ at different cell voltages. At $1 \mathrm{~V}$, the slope of the plot $\log (i) v s . \log (v)$ is 0.96 . Above $1 \mathrm{~V}$, the experimental points are fitted by adding on the whole sweep-rate range a constant value $k$ to the capacitive current $i_{c}$. 

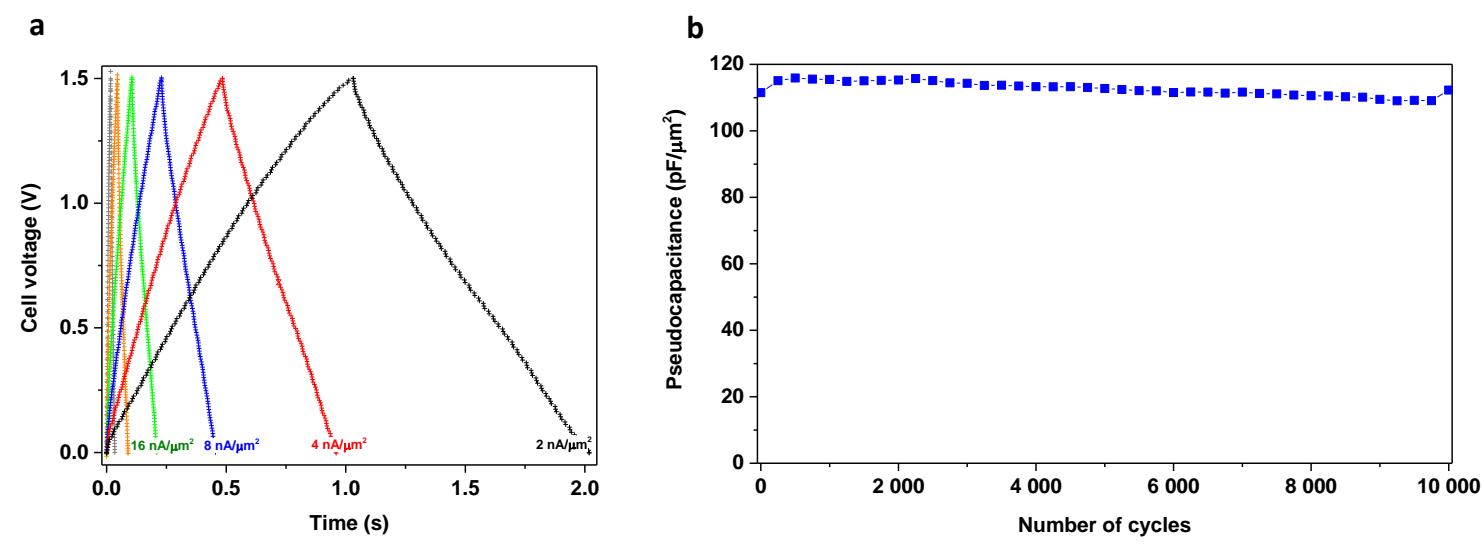

Figure 5. Galvanostatic charge/discharge measurements within a cell voltage of 1.5 V. (a) Even at very high current densities, from 2 to $64 \mathrm{nA} / \mu \mathrm{m}^{2}\left(0.2\right.$ to $\left.6.4 \mathrm{~A} / \mathrm{cm}^{2}\right)$, the curves exhibit a symmetrical triangular profile with negligible IR-drop. (b) Capacitance retention under the severe operating conditions of $8 \mathrm{nA} / \mu \mathrm{m}^{2}\left(0.8 \mathrm{~A} / \mathrm{cm}^{2}\right)$ and $1.5 \mathrm{~V}$. 


\section{ASSOCIATED CONTENT}

\section{Supporting Information.}

Experimental methods, sweep-rate dependence of voltammetric currents, additional figures, and supporting references.

\section{AUTHOR INFORMATION}

Corresponding Author

*E-mail: dpech@laas.fr

\section{ORCID}

David Pech: $\underline{0000-0003-1204-5786}$

Daniel Guay: $\underline{0000-0001-5057-959 X}$

Author Contributions

D.P., A.F. and B.R. conceived and designed the experiments for the elaboration of the electrochemical nanocapacitors. J.F.P. was involved in the Ru deposition. S.G., A.F. and D.G. established the electrochemical oxidation of the Ru. A.F. was involved in the photolithographic process and B.R. in the FIB patterning. A.F., A.E. and D.P. performed the electrochemical characterizations. D.P. wrote the paper and all authors discussed the results and commented on the manuscript.

\section{ACKNOWLEDGMENT}

This work was partly supported by the French RENATECH network and the Canada Research Chair Program.

\section{REFERENCES}


(1) Oudenhoven, J. F. M.; Baggetto, L.; Notten, P. H. L. All-Solid-State Lithium-Ion Microbatteries: A Review of Various Three-Dimensional Concepts. Adv. Energy Mater. 2011, 1, 10-33.

(2) Craighead, H. G. Nanoelectromechanical Systems. Science 2000, 290, 1532-1535.

(3) Wang, Z. L. Self-Powered Nanosensors and Nanosystems. Adv. Mater. 2012, 24, 280-285.

(4) Hu, F.; Cai, Q.; Liao, F.; Shao, M.; Lee, S.-T. Recent Advancements in Nanogenerators for Energy Harvesting. Small 2015, 11, 5611-5628.

(5) Lowy, D. A.; Patrut, A. Nanobatteries: Decreasing Size Power Sources for Growing Technologies. Recent Pat. Nanotech. 2008, 2, 208-219.

(6) Salunkhe, R. R.; Lin, J.; Malgras, V.; Dou, S. X.; Kim, J. H.; Yamauchi, Y. Large-Scale Synthesis of Coaxial Carbon Nanotube/Ni(OH) 2 Composites for Asymmetric Supercapacitor Application. Nano Energy 2015, 11, 211-218.

(7) Salunkhe, R. R.; Tang, J.; Kamachi, Y.; Nakato, T.; Kim, J. H.; Yamauchi, Y. Asymmetric Supercapacitors Using 3D Nanoporous Carbon and Cobalt Oxide Electrodes Synthesized from a Single Metal-Organic Framework. ACS Nano 2015, 9, 6288-6296.

(8) Salanne, M.; Rotenberg, B.; Naoi, K; Kaneko, K.; Taberna, P.-L.; Grey, C. P.; Dunn, B.; Simon, P. Efficient Storage Mechanisms for Building Better Supercapacitors. Nat. Energy 2016, 1, 16070. 
(9) Kyeremateng, N. A.; Brousse, T.; Pech, D. Microsupercapacitors as Miniaturized EnergyStorage Components for On-Chip Electronics. Nat. Nanotech. 2017, 12, 7-15.

(10) Qi, D.; Liu, Y.; Liu, Z.; Zhang, L.; Chen, X. Design of Architectures and Materials in InPlane Micro-supercapacitors: Current Status and Future Challenges. Adv. Mater. 2017, 29, 1602802.

(11) Dinh, T. M.; Armstrong, K.; Guay, D.; Pech, D. High-Resolution On-Chip Supercapacitors with Ultra-High Scan Rate Ability. J. Mater. Chem. A 2014, 2, 7170-7174.

(12) Lobo, D. E.; Banerjee, P. C.; Easton, D. E.; Majumder, M. Miniaturized Supercapacitors: Focused Ion Beam Reduced Graphene Oxide Supercapacitors with Enhanced Performance Metrics. Adv. Energy Mater. 2015, 5, 1500665.

(13) Chaikittisilp, W.; Hu, M.; Wang, H.; Hang, H.-S.; Fujita, T.; Wu, K. C.-W.; Chen, L.-C.; Yamauchi, Y.; Ariga, K. Nanoporous Carbons through Direct Carbonization of a Zeolitic Imidazolate Framework for Supercapacitor Electrodes. Chem. Commun. 2012, 48, 7259-7261.

(14) Salunkhe, R. R.; Kamachi, Y.; Torad, N. L.; Hwang, S. M.; Sun, Z.; Dou, S. X.; Kim, J. H.; Yamauchi, Y. Fabrication of Symmetric Supercapacitors Based on MOF-Derived Nanoporous Carbons. J. Mater. Chem. A 2014, 2, 19848-19854.

(15) Zhuang, X.; Feng, X. Silicon-Compatible Carbon-Based Micro-Supercapacitors. Angew. Chem. Int. Ed. 2016, 55, 6136-6138. 
(16) Huang, P.; Lethien, C.; Pinaud, S.; Brousse, K.; Laloo, R.; Turq, V.; Respaud, M.; Demortière, A.; Daffos, B.; Taberna, P.-L.; et al. On-Chip and Freestanding Elastic Carbon Films for Micro-Supercapacitors. Science 2016, 351, 691-695.

(17) Eustache, E.; Douard, C.; Retoux, R.; Lethien, C.; Brousse, T. $\mathrm{MnO}_{2}$ Thin Films on 3D Scaffold: Microsupercapacitor Electrodes Competing with "Bulk" Carbon Electrodes. Adv. Energy Mater. 2015, 5, 1500680.

(18) Ferris, A.; Garbarino, S.; Guay, D.; Pech, D. 3D $\mathrm{RuO}_{2}$ Microsupercapacitors with Remarkable Areal Energy. Adv. Mater. 2015, 27, 6625-6629.

(19) Bouhtiyya, S.; Lucio Porto, R.; Laïk, B.; Boulet, P.; Capon, F.; Pereira-Ramos, J. P.; Brousse, T.; Pierson, J. F. Application of Sputtered Ruthenium Nitride Thin Films as Electrode Material for Energy-Storage Devices. Scr. Mater. 2013, 68, 659-662.

(20) Pech, D.; Brunet, M.; Durou, H.; Huang, P.; Mochalin, V.; Gogotsi, Y.; Taberna, P.-L.; Simon, P. Ultrahigh-Power Micrometre-Sized Supercapacitors Based on Onion-Like Carbon. Nat. Nanotech. 2010, 5, 651-654.

(21) Liu, W. W.; Feng, Y. Q.; Yan, X. B.; Chen, J. T.; Xue, Q. J. Superior MicroSupercapacitors Based on Graphene Quantum Dots. Adv. Funct. Mater. 2013, 23, 4111-4122.

(22) Thissandier, F.; Gentile, P.; Brousse, T.; Bidan, G.; Sadki, S. Are Tomorrow’s MicroSupercapacitors Hidden in a Forest of Silicon Nanotrees ? J. Power Sources 2014, 269, 740-746. 
(23) Shen, B.; Lang, J.; Guo, R.; Zhang, X.; Yan, X. Engineering the Electrochemical Capacitive Properties of Microsupercapacitors Based on Graphene Quantum Dots/ $\mathrm{MnO}_{2}$ Using Ionic Liquid Gel Electrolytes. ACS Appl. Mater. Interfaces 2015, 7, 25378-25389.

(24) Pech, D.; Brunet, M.; Dinh, T. M.; Armstrong, K.; Gaudet, J.; Guay, D. Influence of the Configuration in Planar Interdigitated Electrochemical Micro-Capacitors. J. Power Sources 2013, 230, 230-235.

(25) Beidaghi, M.; Gogotsi, Y. Capacitive Energy Storage in Micro-Scale Devices: Recent Advances in Design and Fabrication of Micro-Supercapacitors. Energy Environ. Sci. 2014, 7, 867-884.

(26) Hu C. C.; Chen, W. C.; Chang, K. H. How to Achieve Maximum Utilization of Hydrous Ruthenium Oxide for Supercapacitors. J. Electrochem. Soc. 2004, 151, A281-A290.

(27) Miller, J. R.; Outlaw, R. A.; Holloway, B. C. Graphene Double-Layer Capacitor with AC Line-Filtering Performance. Science 2010, 329, 1637-1639.

(28) Sheng, K.; Sun, Y.; Li, C.; Yuan, W.; Shi, G. Ultrahigh-Rate Supercapacitors Based on Electrochemically Reduced Graphene Oxide for AC Line-Filtering. Sci. Rep. 2012, 2, 247.

(29) Wu, Z.; Li, L.; Lin, Z.; Song, B.; Li, Z.; Moon, K.-S.; Wong, C.-P., Bai, S.-L. Alternating Current Line-Filter Based on Electrochemical Capacitors Utilizing Template-Patterned Graphene. Sci. Rep. 2015, 5, 10983.

(30) Wu, Z. S.; Liu, Z.; Parvez, K.; Feng, X.; Müllen, K. Ultrathin Printable Graphene Supercapacitors with AC Line-Filtering Performance. Adv. Mater. 2015, 27, 3669-3675. 
(31) Zheng, J. P.; Huang, C. K. Electrochemical Behavior of Amorphous and Crystalline Ruthenium Oxide Electrodes. J. New Mat. Electrochem. Systems 2002, 5, 41-46.

(32) Dai, Z.; Peng, C.; Chae, J. H.; Ng, K. C.; Chen, G. Z. Cell Voltage Versus Electrode Potential Range in Aqueous Supercapacitors. Sci. Rep. 2015, 5, 9854.

(33) Simon, P.; Gogotsi, Y. Materials for Electrochemical Capacitors. Nat. Mater. 2008, 7, $845-854$.

(34) Bard, A. J.; Faulkner, L. R. Electrochemical Method: Fundamentals and Applications; John Wiley \& Sons: Singapore; 2004. 